\title{
IGNITION PARAMETERS OF DIESEL LAYERS UNDER CONDITIONS OF LOCAL HEATING
}

\author{
Arkadiy V. Zakharevich ${ }^{1, *}$, Mikhail S. Zygin ${ }^{1}$, Pavel V. Panchenko ${ }^{1}$, and Yekaterina A. \\ Vlasova $^{1}$ \\ ${ }^{1}$ National Research Tomsk Polytechnic University, 634050 Tomsk, Russia
}

\begin{abstract}
Describes the methodology and results of experimental studies of ignition of diesel fuel by a single heated up to high temperatures steel particle. The layer thickness of liquid fuel was changed from $1 \mathrm{~mm}$ to 8 $\mathrm{mm}$. It was established dependence of numerical values of the ignition time delay from the thickness layer of diesel fuel. The revealed ignition mode and the limiting layer thickness for diesel fuel when the ignition is missing.
\end{abstract}

\section{Introduction}

It is well-known [1-5] that high temperature metal particles can be applied as ignition sources of solid [1], liquid [2], and dispersed [3] fuels and combustible materials of plant origin [4,5]. The theory about local ignition of solid [6.7] and liquid [8,9] fuels under conditions of local heating has been already developed. At the same time possible is another process the ignition of flammable fluids, when a drop of the distillate fuel is fit in the gas stream or in close proximity to heated to high temperature surfaces of the elements of power plants for various purposes. Methods for developed determination of ignition delay time the fluids in the fall of a fuel drop on a heated surface $[10,11]$ for such of the ignition mode. Now also accumulated extensive information about heat and mass transfer during evaporation of pure liquids from the surfaces of the heating [12, 13]. But these models [6-13] did not explain how ignition characteristics depend on layer thickness. However, the impact of subsurface layer heterogeneity on integral characteristics of ignition was presented in studies $[14,15]$, where structurally inhomogeneous condensed matters were considered.

The aim of this experimental study is how layer thickness of typical liquid fuel impacts on its ignition characteristics by local source of energy.

\section{Experimental technique}

The object of our research is winter diesel fuel. Disc- shaped monolithic steel particles were applied as sources of energy and had fixed sizes: diameter $\left(d_{p}=6 \cdot 10^{-3} \mathrm{~m}\right)$ and height $\left(h_{p}=3 \cdot 10^{-3} \mathrm{~m}\right)$. Particle geometry was accepted to assure minimum dissipation of parameters, which characterize experimental conditions. Experiments was carried out in

\footnotetext{
*Corresponding author: bet@tpu.ru
} 
normal climatic conditions: temperature 290.15-293.15K, atmospheric moisture capacity $50-70 \%$, atmospheric pressure 700-800 mm.Hg. Experimental stand in fig. 1 was used for carried out researches. The conditions of liquid fuel spreading on a solid surface, in the capacity of which was used glass of Petri dish (diameter $d_{v}=10 \cdot 10^{-2} \mathrm{~m}$ and $h_{v}=1.5 \cdot 10^{-2} \mathrm{~m}$.), was simulated. The heated steel particle was in the solid condition and was not deformed during it fall in diesel fuel. Video recording of studying process carried out on high-speed camera Phantom v411 with software "TemaAutomotive". Ignition delay time was determined from the moment of contact particle - diesel layer and appearance of fire by processing video frames. Experiments series (6-8) performed for each liquid fuel layer $(h)$ when the initial temperature of the steel particle $\left(T_{p}\right)$ is fixed. Random error of determining ignition time delay were not more than $\pm 6,7 \%$.

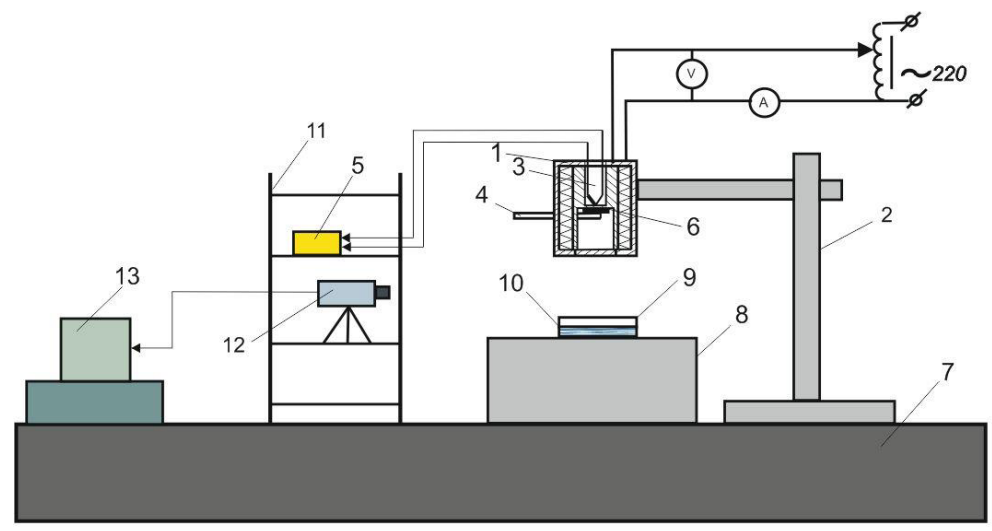

Fig. 1. Scheme of experimental setup: 1 - heating device; 2 - support; 3 - chromel-alumel thermocouple; 4 - ceramic rod; 5 - measuring block with control function electron; 6 - metal particle; 7 - working surface of the experimental setup; 8 - fire-resistant area; 9 - glass dish Petri; 10 - diesel fuel; 11 - shelves metal; 12 - high-speed camera; 13 - touchscreen monitor.

\section{The discussion of experiments' results}

Fig. 2 shows dependences of ignition time delay of diesel fuel versus thickness layer. Two trends in fig. 2 correspond to different values of steel particle temperature. Minimum and maximum values of layer thickness in fig. 2 correspond to limiting conditions of ignition reaction initiation. Extremely high value of layer thickness $(h=7 \mathrm{~mm})$ was quite evident. After fuel evaporation diesel vapours, moved to the oxidant (air) area and heated while flowing steel particle. Then, moving to the low dimension channel, formed above the upper bound of particle, vapours became cool (fig. 3, 4). Energy, which was transfer to vapours from particle at $h>7 \mathrm{~mm}$, was too low to initiate ignition process in consequence of further cool. 


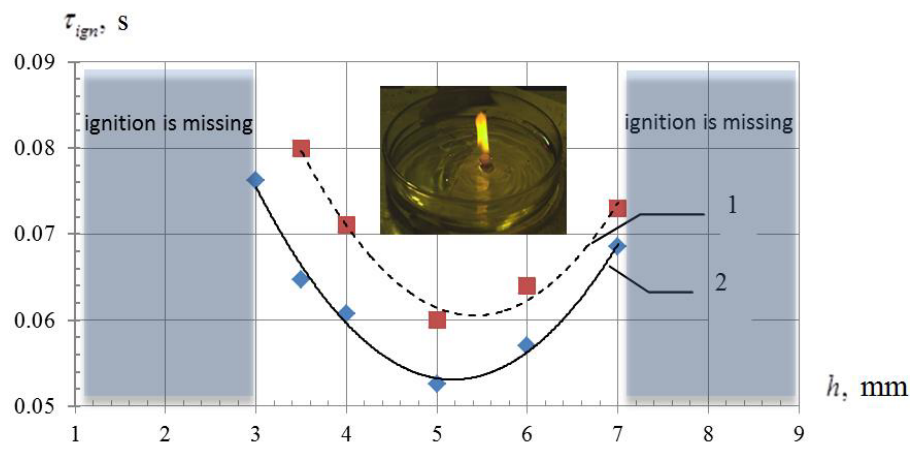

Fig. 2. Experimental dependences of diesel fuel ignition time delay from the thickness of the film: 1 steel particle with a temperature of $1353 \mathrm{~K}, 2$ - steel particle with a temperature of $1373 \mathrm{~K}$.

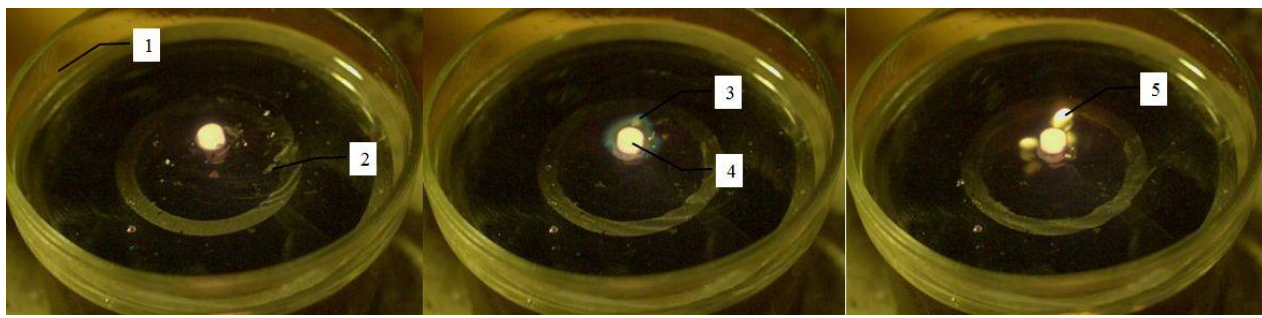

Fig. 3. Video frames of the experiment with ignition of diesel fuel by a steel hot particle: 1 -glass Petri dish; 2 - layer diesel fuel; 3 - pair of diesel fuel; 4 - metal particle; 5 - flame.

Fuel vapours rise up, when the height of vertical channels in the layer is from 3 to 7 $\mathrm{mm}$, and leave out of direct contact with the source of heat energy. As a result fuel vapours shifted toward to particle axis of symmetry and heated by heat exchange with the upper horizontal surface of the particle (fig. 4a). In this case the upper surface was source of active heating of diesel vapours. Experimental video analysis shows that ignition reaction proceeds on symmetry axis of system diesel layer - particle - channel filled with fuel vapours.
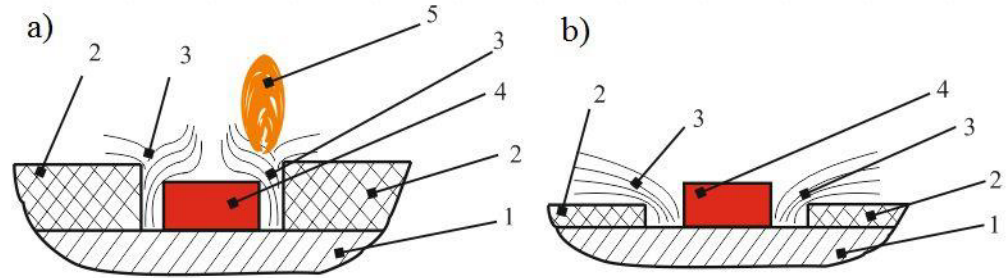

Fig. 4. Options for the location of steel particles in the layer of diesel fuel: a) ignition, b) ignition is missing. 1- the bottom of the Petri dish; 2 - layer diesel fuel; 3 - pair of diesel fuel; 4 - metal particle; 5 - flame.

Probably, left (fig. 2) limited value of $h$ was caused by other reasons. When particle height was bigger than fuel layer, fuel vapours spreaded near the top surface of the heat source and to its opposite side. Consequently, fuel concentration was not sufficient for ignition process activation in the area of the highest air temperatures near the particle axis of symmetry.

Moreover, if particle height was smaller than $h$, fuel layer compresses vapours in the gap at the side surface of the particle due to mass forces. Fuel was heated more intensive. When $h$ was smaller than $h_{p}$, evaporation rate (fig. $4 \mathrm{~b}$ ) of fuel was lower due to an increase 
in the gap thickness. As the results, dry spot was formed around the particle. Fuel evaporated at a low rate at the spot boundaries. The analysis set out in the laws of the experiments shows that the ignition of flammable liquids films by local sources of heat is only possible at certain ratios of thickness $h$ and $h_{p}$. Range relations $\left(h / h_{p}\right) \quad 1 \leq h / h_{p} \leq 2.3$ comply with the conditions of diesel fuel ignition.

\section{Conclusions}

According to the experimental results, the limiting modes and thickness of diesel layers ignition under conditions of local heating were established. Physical model of heat and mass transfer when igniting the diesel fuel layers by high temperature particles was formulated.

\section{References}

1. A.V. Zakharevich, G.V. Kuznetsov, V.I. Maksimov, V.T. Kuznetsov, Combustion, Explosion, and Shock Waves. 44, 543 (2008)

2. G.V. Kuznetsov, P.A. Strizhak, J. Eng.Thermophys. 17, 224 (2008)

3. A.V. Zakharevich, A.R. Bogomolov, J. Phys. Chem. B 9, 907 (2015)

4. A.V. Zakharevich, N.V. Baranovskiy, J. Phys. Chem. B 9, 911 (2015)

5. A.V. Zakharevich, J. Eng. Phys. Thermophys. 87, 98 (2014)

6. G.V. Kuznetsov, G.Ya. Mamontov, G.V. Taratushkina, Combustion, Explosion and Shock Waves 40, 70 (2004)

7. G.V. Kuznetsov, G.Ya. Mamontov, G.V. Taratushkina, Khim. Fiz. 23, 67 (2004)

8. O.V. Vysokomornaya, G.V. Kuznetsov, P.A. Strizhak, Russ. J. Phys. Chem. B 5, 668 (2011)

9. D.O. Glushkov, J.-C. Legros, P.A. Strizhak, A.V. Zakharevich, Fuel 175, 105 (2016)

10. P. Dagaut and M. Cathonnet, Prog. Energy Combust. Sci. 32, 48 (2016)

11. G.V. Kuznetsov, A.V. Zakharevich, N.S. Belkov, Chem. Pet. Eng. 50, 424 (2014)

12. G.V. Kuznetsov, D.V. Feoktistov, E.G. Orlova, Thermophysics and Aeromechanics 23, 17 (2016)

13. Y.V. Lyulin, D.V. Feoktistov, I.A. Afanas'ev, E.S. Chachilo, O.A. Kabov, G.V. Kuznetsov, Tech. Phys. Lett. 41, 665 (2015)

14. V.L. Strakhov, A.N. Garashchenko, G.V. Kuznetsov and V.P. Rudzinskii, Combustion, Explosion, and Shock Waves 37, 178 (2001)

15. D.O. Glushkov, G.V. Kuznetsov, P.A. Strizhak, Russ. J. Phys. Chem. B 5, 1000 (2011) 